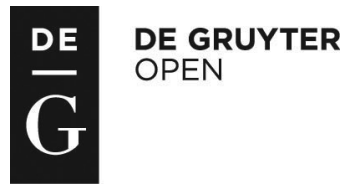

\title{
CONDITION OF SOWS DURING REPRODUCTIVE ACTIVITY DEPENDING ON LIPID METABOLISM GENE (DGAT1) POLYMORPHISM*
}

\author{
Magdalena Szyndler-Nędza ${ }^{\star \bullet}$, Katarzyna Piórkowska², Katarzyna Ropka-Molik² \\ ${ }^{1}$ Department of Animal Genetics and Breeding, \\ ${ }^{2}$ Laboratory of Genomics, \\ National Research Institute of Animal Production, 32-083 Balice n. Kraków, Poland \\ •Corresponding author: magdalena.szyndler@izoo.krakow.pl
}

\begin{abstract}
Mutations at gene loci associated with body lipid metabolism may affect not only carcass and meat quality traits in young animals but also the production results of mother sows. The objective of the study was to determine the effect of mutations in the $D G A T 1$ gene, found in Polish populations of maternal breeds, on condition of gilts and later on condition and reproductive performance of sows during three reproductive cycles. The study involved 118 gilts of maternal breeds (Polish Large White (PLW) and Polish Landrace (PL)). Gilts and subsequently sows were monitored for body weight $(\mathrm{BW})$ and $\mathrm{P} 2$ backfat thickness over three reproductive cycles and their litters were analysed for the number and body weight of the piglets. A total of 354 litters of pigs were evaluated. In the analysed pig populations, a single mutation $(A / G)$ in the $D G A T 1$ gene (rs45434075) had a significant effect on deposition of subcutaneous fat only in the $\mathrm{PLW}$ gilts $\left(\mathrm{P} 2_{\mathrm{G}}, A A, A G<G G \mathrm{P} \leq 0.05\right.$ and $\left.P 2_{\mathrm{F}} \mathrm{r}=214 \mathrm{P} \leq \mathbf{0 . 0 1}\right)$. As regards the $G / A$ 3'UTR polymorphism of the $D G A T 1$ gene (rs342152658), this mutation is negatively correlated only in the PL sows with fatness during their reproductive life and with $\mathrm{BW}$ of the piglets reared to $21 \mathrm{~d}$ of age. Sows of the DGAT1 ${ }^{G G}$ 3'UTR genotype had significantly lower $P 2_{F}$ backfat thickness $(\mathrm{P} \leq \mathbf{0 . 0 5})$ and, during a 21-d lactation, reared lighter piglets $(\mathrm{P} \leq 0.01)$ compared to sows of the same breed with the $D G A T 1^{A G}$ 3'UTR genotype. The analysed traits were also affected by the interaction between mutations in the $D G A T 1$ gene of the sows of maternal breeds (DGAT1/DGAT1 3'UTR). Sows of the $D G A T 1^{G G / G G}$ genotype were characterised by the highest backfat thickness on selection day, and during three reproductive cycles they reared significantly more piglets compared to sows of the $D G A T 1^{A A / A G}$ genotype. Heterozygous sows $(A G / A G)$ reared significantly heavier piglets than sows of the $A A / G G$ and $A G / G G$ genotypes (P $\leq$ 0.05).
\end{abstract}

Key words: condition, rearing of piglets, three reproductive cycles, $D G A T 1 A / G, D G A T 1 G / A 3^{\prime} U T R$

\footnotetext{
* Work financed from statutory activity, project no. 01-4.07.1.
} 
The quality of pig carcasses and meat is increasingly being considered as a selection trait in young animals. This trait is strictly related to the content of protein and fat, including subcutaneous and intramuscular fat (IMF) (Hausman et al., 2009). The fatness of animals depends on both environmental factors and animal genotype. One of the genes affecting the body's lipid metabolism is the diacylglycerol acyltransferase 1 (DGAT1) gene. It has been mapped on chromosome 4, in a region with around 200 QTLs for backfat thickness, weight gains, carcass fatness and fatty acid composition, among others (Szczerbal et al., 2007). The DGAT1 gene codes for the microsomal enzyme DGAT1. This enzyme catalyses the final step of the synthesis of triglycerides which, together with free fatty acids, are one of the main energy sources used by the body or stored as a reserve in the form of adipose tissue (Buhman et al., 2002; Lopaschuk et al., 2010).

There are few studies that have considered the effect of DGAT1 polymorphism on the productive traits of pigs. Zuo Zuo (2008) showed the presence of A3122G as well as C7545T, C7604T and 3'-UTR (G $\rightarrow$ A, Eco47III) mutations in the Chinese populations of native pigs and in the Duroc, Yorkshire and Landrace breeds. The same author also observed that the analysed mutations had a highly significant effect on lower P2 backfat thickness, fat percentage and the degree of marbling. In the Czech Large White breed. Weisz et al. (2011) found the effect of the DGAT1 $A / G$ gene (determined according to Nonneman and Rohrer, 2002) on carcass meat percentage (AG>AA). In the Canadian population of commercial pigs, Zhang et al. (2014) demonstrated that the DGAT1 C1230T gene polymorphism has a statistically significant effect on the physicochemical traits of meat, namely drip loss and probe yield. The latest research shows that the DGAT1 gene is also involved in triglyceride synthesis in sow milk (Lv et al., 2015). Szyndler-Nędza and Piórkowska (2015) found the DGAT1 $A / G$ (rs45434075) polymorphism to affect the fat content of colostrum in PL sows, as well as the protein and lactose content of milk in PLW sows.

Production results of the sows depend primarily on their condition (body weight (BW), fatness) during gestation (Matysiak et al., 2007; Wientjes et al., 2013; Decaluwe et al., 2013). Due to selection of the pig population for reduced fatness, the presence of animals with high lean percentage (low in fat) may adversely affect reproductive performance of the sows because their fatness level during the reproductive cycle has an effect on their blood and milk biochemical parameters (Rekiel et al., 2011). For the above reasons, when analysing the effect that the relationships between mutations at gene loci associated with the body's fat metabolism have on carcass and meat quality traits in young animals, it is necessary to estimate the effect of these mutations on the reproductive performance of the sows retained for further breeding.

The objective of our study was to determine the effect of DGAT1 mutations in the Polish populations of maternal breeds on the condition (BW and P2 backfat thickness) of young animals (gilts) and later on the condition and reproductive performance of the sows during three reproductive cycles. 


\section{Material and methods}

\section{Animals}

The study was carried out at the Experimental Station of the National Research Institute of Animal Production in Żerniki Wielkie. The experimental subjects were 55 PLW gilts and 63 PL gilts.

\section{Phenotypic data collection}

Between 150 and 210 (approx. 180) d of age gilts included in the study were weighed and measured for P2 backfat thickness using a Piglog 105 ultrasonic device. The $\mathrm{P} 2$ position is located behind the last rib, at the junction of the thoracic and lumbar vertebrae, $3 \mathrm{~cm}$ off the midline. The data were expressed as the BW of the gilts $\left(\mathrm{BW}_{\mathrm{G}}\right)$ and backfat thickness of the gilts $\left(\mathrm{P} 2_{\mathrm{G}}\right)$. Next, prior to mating $\left(_{\mathrm{M}}\right)$, prior to farrowing $\left(_{F}\right)$ and after weaning of the piglets $\left({ }_{W}\right)$, each sow was analysed for BW and $\mathrm{P} 2$ backfat thickness. These measurements were made over three consecutive reproductive cycles (RC) of the sows. In each parity, age at first farrowing (AFF), the farrowing interval (FI), the number of piglets at 1 and $21 \mathrm{~d}$ of age (NPB and NP21), and piglet weight at 1 and $21 \mathrm{~d}$ of age (WPB and WP21) were determined. A total of 168 litters of PLW pigs and 186 litters of PL pigs were evaluated. The sows and piglets were kept in piggeries under standard climate conditions. They received the same complete feeds in rations formulated according to the requirements of each technological group. The sows were also subjected to flush feeding.

\section{Determination of $D G A T 1$ polymorphisms}

DNA was isolated from leukocytes with the use of the Genomic Wizard Purification Kit (Promega, Madison, WI, USA). Mutation in the DGAT1 gene was determined with PCR-RFLP methods according to Nonneman and Rohrer (2002), with modification of the primer pair, which was designed in Primer 3 (http://biotools. umassmed.edu/bioapps/primer3_www.cgi). Forward-GCATCCTGAATTGGTGTGTG and Reverse-GGCCATTCAGAACAG primers amplified a 257 bp PCR product, which was then digested with $A v a$ II restriction enzyme, which recognises $A / G$ rs45434075 (g. $32748 \mathrm{~A}>\mathrm{G}(\mathrm{NW} 003534570.2)$ ) substitution.

Mutation in the NC_010446.4:g.609236G>ADGAT1 (rs342152658) gene was determined using the PCR-RFLP method and primers F:TGGTCCATGCTGCCTCCT and R: AACCTCCCTCAACCTGCTG. A PCR product with 192 base pairs was digested by the AvaI enzyme into two bands - 134 and 92 bp. This enzyme recognises a single substitution of G or A in 3'UTR in position 1894 of the DGAT1 transcript.

\section{Statistical analysis}

The data were statistically analysed using the procedures of Statistica version 10 (2011, StatSoft Inc.). The differences between groups were estimated according to the following statistical model: 


$$
y_{i j k l}=a_{i}+b_{j}+c_{k}+d_{l}+f_{(a b c)+} e_{i j k l}
$$

where:

$y_{i j k l}$ - trait observation of $i j k l$-th individual,

$a_{i}=$ fixed effect of $i$-th breed $(i=1,2)$,

$b_{j}=$ fixed effect of $j$-th genotype $D G A T 1 A / G(k=1,2,3)$,

$c_{k}=$ fixed effect of $k$-th genotype DGAT1 G/A 3'UTR $(1=1,2,3)$,

$d_{l}=$ random effect of 1 -th lactation $(1=1,2,3)$,

$f_{(a b c)}=$ interaction between factors (a - breed, b-genotype DGAT1 A/G, c-genotype DGAT1 G/A 3'UTR).

The differences between the means of individual traits were tested using NIR Fisher's multiple range test. Spearman's correlations were estimated between the $A / G$ and $G / A 3^{\prime} U T R$ mutations in the DGAT1 gene and the values of the analysed traits in three lactations. To this end, the genotypes of both genes were coded as numbers (DGAT1 $A A-1, A G-2, G G-3)$.

\section{Results}

\section{Characteristics of the animals}

The frequencies of DGAT1A/G and DGAT1G/A 3'UTR genotypes in the PL and PLW breeds are presented in Table 1. The DGAT1 $A / G$ mutation at position 103 of intron 2 was represented in both maternal breeds by three genotypes ( $A A, A G, G G)$. In both breeds, most animals carried allele $D G A T 1^{A}$, with $D G A T 1^{A G}$ genotype being most numerous in the PL breed and DGAT1 ${ }^{A A}$ in the PLW breed. For the DGAT1 G/A $3^{\prime} U T R$ polymorphism, most PL animals had the $D G A T 1^{G G}(88.89 \%)$ and DGAT1 ${ }^{A G}$ (9.52\%) genotypes, while the PLW breed carried only two genotypes: GG $(96.36 \%)$ and AG (3.64\%). Analysis of the frequency of genotypes of the above polymorphisms in the DGAT1 gene - in accordance with the Hardy-Weinberg law - showed that both breeds were at genetic equilibrium.

Table 1. Frequency of the DGAT1 A/G and DGAT1 G/A 3' UTR genotypes in the PLW and PL breeds

\begin{tabular}{|c|c|c|c|c|c|}
\hline \multirow{2}{*}{ Gene/breed } & \multirow{2}{*}{ Genotype } & \multirow{2}{*}{ No. of sows } & \multicolumn{2}{|c|}{ Frequency } & \multirow{2}{*}{$\begin{array}{c}\text { HWE } \\
\text { P-value }\end{array}$} \\
\hline & & & genotype & allele & \\
\hline 1 & 2 & 3 & 4 & 5 & 6 \\
\hline \multirow[t]{3}{*}{$\overline{D G A T 1 / P L}$} & $A A$ & 14 & 24.14 & A 53.06 & 0.1452 \\
\hline & $A G$ & 33 & 56.90 & & \\
\hline & $G G$ & 11 & 18.97 & G 46.94 & \\
\hline \multirow[t]{3}{*}{$D G A T 1 / P L W$} & $A A$ & 25 & 47.17 & A 70.2 & 0.3897 \\
\hline & $A G$ & 24 & 45.28 & & \\
\hline & $G G$ & 4 & 7.55 & G 29.8 & \\
\hline \multirow[t]{3}{*}{$D G A T 1 / P L$ and $P L W$} & $A A$ & 39 & 33.14 & A 60.31 & 0.3333 \\
\hline & $A G$ & 57 & 51.35 & & \\
\hline & $G G$ & 15 & 13.51 & G 39.69 & \\
\hline
\end{tabular}


Table 1 - contd.

\begin{tabular}{|c|c|c|c|c|c|}
\hline 1 & 2 & 3 & 4 & 5 & 6 \\
\hline \multirow[t]{3}{*}{ DGAT1 3'/PL } & $A A$ & 1 & 1.59 & A 5.61 & 0.1874 \\
\hline & $A G$ & 6 & 9.52 & & \\
\hline & $G G$ & 56 & 88.89 & G 94.39 & \\
\hline \multirow[t]{3}{*}{ DGAT1 3'/PLW } & $A A$ & & - & A 1.52 & 0.8783 \\
\hline & $A G$ & 2 & 3.64 & & \\
\hline & $G G$ & 53 & 96.36 & G 98.48 & \\
\hline \multirow[t]{3}{*}{$D G A T 13^{\prime} / P L$ and $P L W$} & $A A$ & 1 & 0.85 & A 3.06 & 0.7546 \\
\hline & $A G$ & 8 & 6.78 & & \\
\hline & $G G$ & 109 & 92.37 & G 96.94 & \\
\hline DGAT1/DGAT1 3' & $A A / A A$ & 1 & 0.93 & & \\
\hline \multirow[t]{8}{*}{ PL and PLW } & $A A / A G$ & 4 & 3.74 & & \\
\hline & $A A / G G$ & 33 & 30.84 & & \\
\hline & $A G / A A$ & & - & & \\
\hline & $A G / A G$ & 4 & 3.74 & & \\
\hline & $A G / G G$ & 50 & 46.73 & & \\
\hline & $G G / A A$ & & - & & \\
\hline & $G G / A G$ & & - & & \\
\hline & $G G / G G$ & 15 & 14.02 & & \\
\hline
\end{tabular}

PL - Polish Landrace breed, PLW - Polish Large White breed, HWE - Hardy-Weinberg equilibrium.

The effect of breed (PL, PLW) on BW and P2 backfat thickness of the sows and on their reproductive performance in three reproductive cycles

Table 2 shows the breed effect on the condition of the gilts, on the subsequent condition of the sows during three reproductive cycles, and on the number and BW of the reared piglets. On the performance test day, the gilts of both breeds had similar BW and P2 backfat thickness. During the three reproductive cycles, however, the PLW sows, when compared to the PL sows, achieved significantly higher $(\mathrm{P} \leq 0.01)$ mean BW and, at the same time, significantly lower $(\mathrm{P} \leq 0.01) \mathrm{P} 2$ backfat thickness at each stage of the reproductive cycle.

Table 2. The effect of breed (PL, PLW) on BW and P2 backfat thickness of the sows and on their reproductive performance in three reproductive cycles $(\mathrm{RC})$

\begin{tabular}{|c|c|c|c|c|}
\hline \multirow{2}{*}{ Trait } & \multirow{2}{*}{ Symbol } & \multicolumn{2}{|c|}{$\mathrm{RC}$} & \multirow{2}{*}{$\frac{\text { P-value }}{\text { PL/PLW }}$} \\
\hline & & PL & PLW & \\
\hline Body weight of gilts & $\mathrm{BW}_{\mathrm{G}}(\mathrm{kg})$ & $100.29 \pm 6.40$ & $101.54 \pm 8.21$ & 0.1203 \\
\hline P2 backfat thickness of gilts & $\mathrm{P} 2_{\mathrm{G}}(\mathrm{mm})$ & $9.00 \pm 1.36$ & $8.89 \pm 1.69$ & 0.5283 \\
\hline Body weight on mating day & $\mathrm{BW}_{\mathrm{M}}(\mathrm{kg})$ & $168.04 \pm 33.34$ & $174.66 \pm 36.74$ & 0.0047 \\
\hline P2 backfat thickness on mating day & $\mathrm{P} 2_{\mathrm{M}}(\mathrm{mm})$ & $13.87 \pm 3.53$ & $12.83 \pm 3.52$ & 0.0020 \\
\hline Body weight on farrowing day & $\mathrm{BW}_{\mathrm{F}}(\mathrm{kg})$ & $206.63 \pm 30.94$ & $215.61 \pm 36.67$ & 0.0016 \\
\hline P2 backfat thickness on farrowing day & $\mathrm{P} 2_{\mathrm{F}}(\mathrm{mm})$ & $17.92 \pm 4.49$ & $16.14 \pm 4.77$ & 0.0006 \\
\hline Body weight on weaning day & $\mathrm{BW}_{\mathrm{W}}(\mathrm{kg})$ & $194.35 \pm 25.57$ & $203.21 \pm 31.76$ & 0.0002 \\
\hline P2 backfat thickness on weaning day & $\mathrm{P} 2_{\mathrm{W}}(\mathrm{mm})$ & $14.54 \pm 3.65$ & $13.50 \pm 3.96$ & 0.0104 \\
\hline Age at first farrowing & AFF (days) & $360.60 \pm 48.84$ & $357.65 \pm 52.31$ & 0.5849 \\
\hline Farrowing interval & FI (days) & $161.51 \pm 35.26$ & $161.53 \pm 38.01$ & 0.9975 \\
\hline Number of piglets born & NPB (head) & $11.51 \pm 1.33$ & $11.74 \pm 1.03$ & 0.0911 \\
\hline Weight of piglet born & WPB (kg) & $1.47 \pm 0.16$ & $1.44 \pm 0.16$ & 0.0716 \\
\hline Number of piglets on day 21 & NP21 (head) & $10.33 \pm 1.54$ & $10.41 \pm 1.51$ & 0.8471 \\
\hline Weight of piglet on day 21 & WP21 (kg) & $5.59 \pm 0.67$ & $5.52 \pm 0.65$ & 0.3077 \\
\hline
\end{tabular}




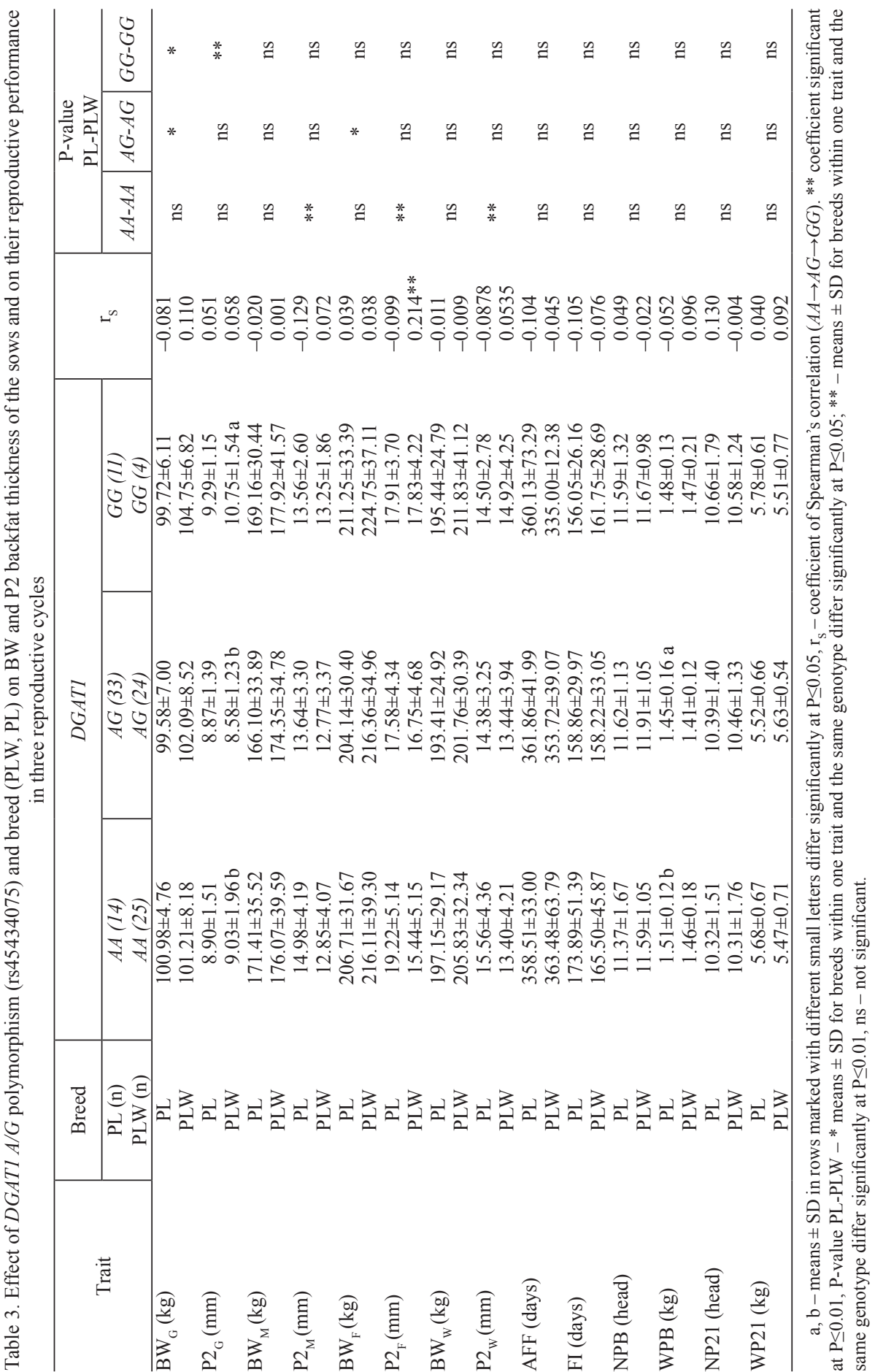




\section{Effect of breed (PLW, PL) and DGAT1 locus polymorphism on BW and P2 backfat thickness of the sows and on their reproductive performance in three reproductive cycles}

Table 3 presents the effect of the interaction between breed and DGAT1 A/G polymorphism on the analysed traits. The letters indicate significant within-breed differences between the genotypes, and asterisks denote significant between-breed differences within the same genotypes. Analysis of the animals of the same genotype showed that on the performance test day, the PLW gilts (DGAT1 ${ }^{A G}$ and $\left.D G A T 1^{G G}\right)$ were characterised by significantly higher BW compared to the PL gilts of the same genotype. In turn, the PLW gilts of the $D G A T 1^{G G}$ genotype had significantly $(\mathrm{P} \leq 0.05)$ higher $\mathrm{P} 2_{\mathrm{G}}$ backfat thickness compared to other animals of that breed and to the PL gilts of the same genotype $\left(D G A T 1^{G G}\right)$. Significant differences were also found between the PLW and PL animals of the DGAT1 ${ }^{A A}$ genotype for P2 backfat thickness in each period of the reproductive cycle $\left(\mathrm{P} 2_{\mathrm{M}}, \mathrm{P} 2_{\mathrm{F}}, \mathrm{P} 2_{\mathrm{W}}, \mathrm{PLW}<\mathrm{PL}, \mathrm{P} \leq 0.01\right)$. When analysing the number and $\mathrm{BW}$ of the piglets, it was found that during the three reproductive cycles the PL sows of the DGAT1 ${ }^{A A}$ genotype gave birth to significantly heavier piglets compared to the PL sows of the $D G A T 1^{A G}$ genotype. The coefficients of Spearman's correlation - as shown in the table - between DGAT1 polymorphism and the analysed traits show the presence of a positive correlation only in the PLW breed between DGAT1 and $\mathrm{P} 2$ backfat thickness measured on the day of farrowing $\left(\mathrm{P} 2{ }_{\mathrm{F}} A A \rightarrow A G \rightarrow G G, \mathrm{P} \leq 0.01\right)$.

Table 4 gives the effects of breed and mutation at the DGAT1 G/A 3'UTR locus in the sows of maternal breeds on the analysed traits. Because the DGATAA $3^{\prime} \mathrm{UTR}$ genotype in the PL breed and $D G A T 1^{A G}$ in the PLW breed occurred in only single individuals (one and two animals, respectively), these results were disregarded in the significance analysis. In the PL sows, the effect of this polymorphism in the DGAT1 gene occurred for two traits: P2 backfat thickness on farrowing day and the BW of the piglets on $\mathrm{d} 21$ of age. Sows of the $D G A T 1^{G G} 3^{\prime} \mathrm{UTR}$ genotype were characterised by significantly lower $\mathrm{P} 2_{\mathrm{F}}$ backfat thickness $(\mathrm{P} \leq 0.05)$ and reared significantly lighter piglets over a $21-\mathrm{d}$ lactation $(\mathrm{MP} 21, \mathrm{P} \leq 0.01)$ compared to sows of this breed with the DGAT1 ${ }^{A G}$ 3'UTR genotype. Based on the coefficients of Spearman's correlation estimated for the PLW sows, a negative relationship was found between $G / A$ mutation in the DGAT1 3'UTR gene and backfat thickness on selection day $\left(\mathrm{P} 2_{\mathrm{G}}, \mathrm{P} \leq 0.01\right)$ and during the consecutive periods of the reproductive cycle of the sows $\left(\mathrm{P} 2_{\mathrm{M}}, \mathrm{P} 2_{\mathrm{F}}, \mathrm{P} 2_{\mathrm{W}}, A A \rightarrow A G \rightarrow G G, \mathrm{P} \leq 0.01\right)$. A significantly negative correlation was also observed between this polymorphism and the weight of the weaned piglets (WP21, $A A \rightarrow A G \rightarrow G G, \mathrm{P} \leq 0.05$ ). Analysis of the effect of breed (PLW, PL) in the sows of the DGAT1 ${ }^{G G}$ 3'UTR genotype on the analysed traits revealed that the PLW sows, compared to the PL sows, were characterised by significantly higher BW on selection day $\left(\mathrm{BW}_{\mathrm{G}}, \mathrm{PLW}>\mathrm{PL}, \mathrm{P} \leq 0.05\right)$, and later on farrowing day $(\mathrm{BW}, \mathrm{P} \leq 0.01)$ and weaning day $\left(\mathrm{BW}_{\mathrm{W}}, \mathrm{P} \leq 0.05\right)$. At the same time, the PLW sows, when compared to PL sows, had significantly lower P2 backfat thickness on the day of mating and on the day of farrowing $\left(\mathrm{P} 2_{\mathrm{M}}, \mathrm{P} 2_{\mathrm{F}}, \mathrm{PLW}<\mathrm{PL}, \mathrm{P} \leq 0.05\right)$. 


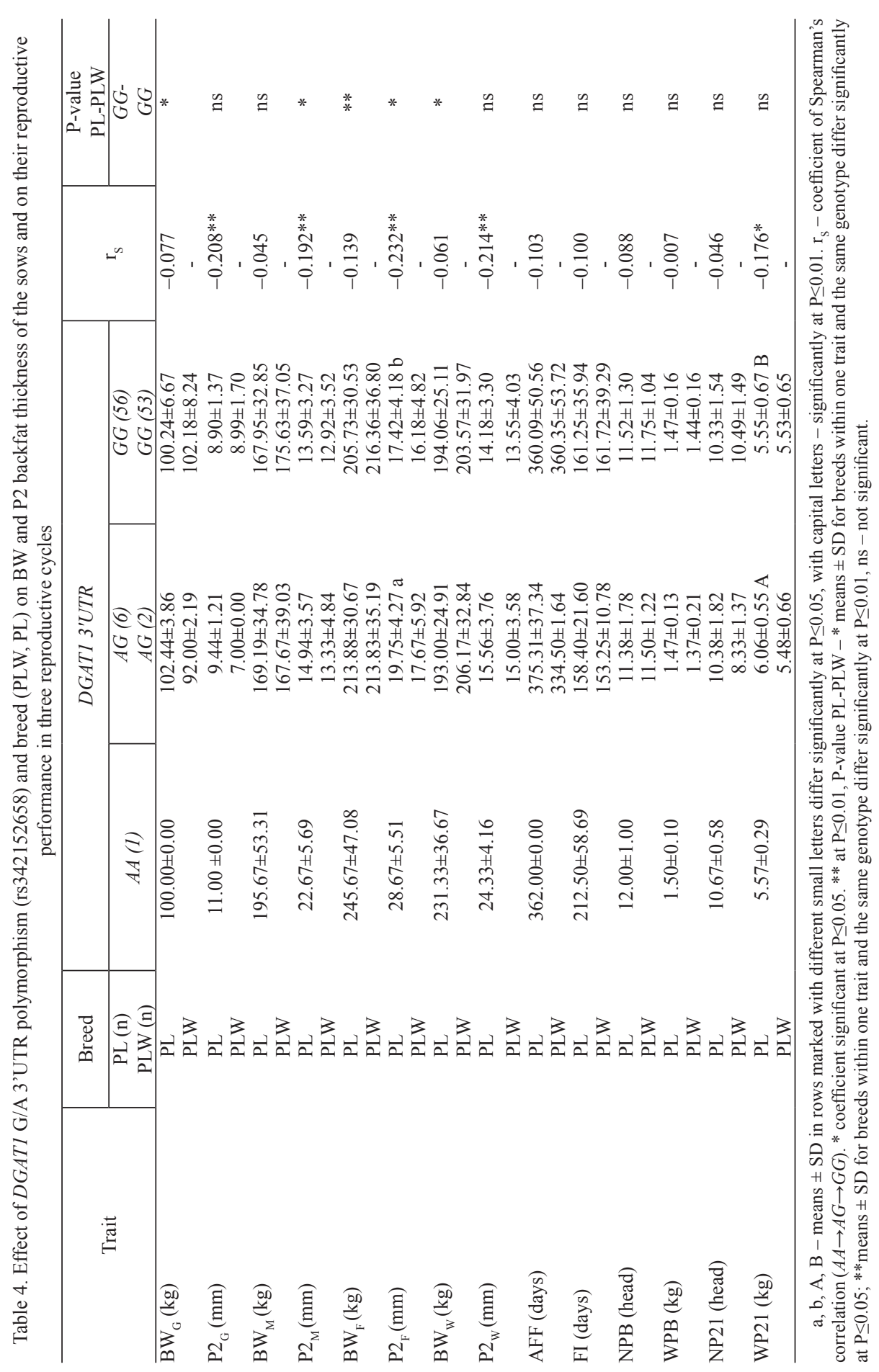




\section{Effect of interaction between mutations at the $D G A T 1$ locus on $\mathrm{BW}$ and $\mathrm{P2}$} backfat thickness in maternal breeds and on their reproductive performance in three reproductive cycles

Table 5 shows the effect of the interaction between mutations in the DGAT1 gene on the BW and P2 backfat thickness of sows on selection day and during three reproductive cycles. The table lists the genotypes found in at least four animals. The presented data show that the interaction between two DGAT1 polymorphisms $(A / G$ and $G / A 3^{\prime} U T R$ ) has an effect mainly on P2 backfat thickness in the sows. On the day of selection of the young animals, individuals with the $D G A T 1^{G G / G G}$ genotype had significantly thicker $\mathrm{P} 2_{\mathrm{G}}$ backfat $(\mathrm{P} \leq 0.05)$ compared to most of the genotypes under analysis. On farrowing day, females of the $D G A T 1^{A A / G G}$ genotype showed significantly $(\mathrm{P} \leq 0.01, \mathrm{P} \leq 0.05)$ lower backfat thickness $\left(\mathrm{P} 2_{\mathrm{F}}\right)$ compared to sows with the other genotypes. Also, on the day of weaning, the $D G A T 1^{A A / G G}$ sows had the lowest backfat thickness $\left(\mathrm{P} 2_{\mathrm{w}}\right)$, with a significant difference only when compared to sows of the $D G A T 1^{A A / A G}$ genotype $(\mathrm{P} \leq 0.05)$. As regards the number of piglets born and reared, sows of the $D G A T 1^{A A / A G}$ genotype gave birth to significantly $(\mathrm{P} \leq 0.05)$ fewer piglets compared to the $D G A T 1^{A G / A G}$ and $D G A T 1^{A G / G G}$ sows, as well as reared fewer piglets until $21 \mathrm{~d}$ of lactation compared to homozygous sows of the $D G A T 1^{G G / G G}$ genotype $(\mathrm{P} \leq 0.05)$. Analysis of the $\mathrm{BW}$ of the piglets born and reared showed that sows of the analysed genotypes gave birth to piglets of similar birth weight (from $1.42 \mathrm{~kg}$ to 1.48 $\mathrm{kg}$ ), but piglets born to sows with the $D G A T 1^{A G / A G}$ genotype had significantly higher body weight on $\mathrm{d} 21$ of age, with a significant difference in relation to piglets born to sows with the $D G A T 1^{A A / G G}$ and $D G A T 1^{A G / G G}$ genotypes $(\mathrm{P} \leq 0.05)$.

Table 5. Effect of interaction between mutations at the DGAT1 locus on BW and P2 backfat thickness of maternal breeds and on their reproductive performance in three reproductive cycles

\begin{tabular}{|c|c|c|c|c|c|}
\hline \multirow{3}{*}{$\mathrm{n}$} & \multicolumn{5}{|c|}{ DGAT1/DGAT1 3UTR } \\
\hline & $A A / A G$ & $A A / G G$ & $A G A G$ & $A G / G G$ & $G G / G G$ \\
\hline & 4 & 33 & 4 & 50 & 15 \\
\hline $\mathrm{BW}_{\mathrm{G}}(\mathrm{kg})$ & $98.5 \pm 6.31$ & $101.7 \pm 7.2$ & $100.7 \pm 5.4$ & $100.9 \pm 8.1$ & $101.1 \pm 6.63$ \\
\hline $\mathrm{P} 2_{\mathrm{G}}(\mathrm{mm})$ & $8.36 \pm 1.57 \mathrm{a}$ & $8.96 \pm 1.84 \mathrm{a}$ & $9.18 \pm 1.40$ & $8.70 \pm 1.35 \mathrm{a}$ & $9.68 \pm 1.41 \mathrm{~b}$ \\
\hline $\mathrm{BW}_{\mathrm{M}}(\mathrm{kg})$ & $163.5 \pm 37.7$ & $175.4 \pm 37.9$ & $174.1 \pm 33.0$ & $170.1 \pm 34.8$ & $171.5 \pm 33.5$ \\
\hline $\mathrm{P} 2_{\mathrm{M}}(\mathrm{mm})$ & $14.18 \pm 4.09$ & $13.18 \pm 3.91$ & $14.82 \pm 3.87$ & $13.29 \pm 3.31$ & $13.47 \pm 2.40$ \\
\hline $\mathrm{BW}_{\mathrm{F}}(\mathrm{kg})$ & $208.8 \pm 36.2$ & $212.7 \pm 36.9$ & $218.9 \pm 28.8$ & $209.5 \mathrm{a} \pm 33.2$ & $214.9 b \pm 34.5$ \\
\hline $\mathrm{P} 2_{\mathrm{F}}(\mathrm{mm})$ & $19.64 \pm 4.72 \mathrm{~B}$ & $15.88 \pm 4.88 \mathrm{Aa}$ & $18.73 \pm 4.90 \mathrm{~b}$ & $17.22 \pm 4.49 \mathrm{~b}$ & $17.89 \pm 3.79 \mathrm{~b}$ \\
\hline $\mathrm{BW}_{\mathrm{W}}(\mathrm{kg})$ & $192.3 \pm 29.4$ & $203.3 \pm 31.5$ & $200.9 \pm 25.36$ & $197.2 \pm 27.7$ & $199.9 \pm 30.5$ \\
\hline $\mathrm{P} 2_{\mathrm{W}}(\mathrm{mm})$ & $15.55 \pm 3.93 \mathrm{~b}$ & $13.53 \pm 3.93 \mathrm{a}$ & $15.28 \pm 3.50$ & $13.98 \pm 3.59$ & $14.61 \pm 3.20$ \\
\hline AFF (days) & $10.90 \pm 2.17 \mathrm{a}$ & $11.57 \pm 1.20$ & $11.91 \pm 0.54 \mathrm{~b}$ & $11.76 \pm 1.15 b$ & $11.61 \pm 1.22$ \\
\hline FI (days) & $1.46 \pm 0.20$ & $1.48 \pm 0.16$ & $1.42 \pm 0.12$ & $1.44 \pm 0.15$ & $1.48 \pm 0.16$ \\
\hline NPB (head) & $10.90 \mathrm{a} \pm 2,17$ & $11.57 \pm 1,20$ & $11.91 \mathrm{~b} \pm 0,54$ & $1176 \mathrm{~b} \pm 1,15$ & $11.61 \pm 1,22$ \\
\hline WPB (kg) & $1.46 \pm 0,20$ & $1.48 \pm 0,16$ & $1.42 \pm 0,12$ & $1.44 \pm 0,15$ & $1.48 \pm 0,16$ \\
\hline NP21 (head) & $9.55 \pm 2.30 \mathrm{~b}$ & $10.40 \pm 1.61$ & $10.09 \pm 1.51$ & $10.45 \pm 1.38$ & $10.64 \pm 1.64 \mathrm{a}$ \\
\hline WP21 (kg) & $5.87 \pm 0.87$ & $5.50 \pm 0.68 \mathrm{~b}$ & $5.91 \pm 0.31 \mathrm{a}$ & $5.53 \pm 0.63 b$ & $5.69 \pm 0.66$ \\
\hline
\end{tabular}

$\mathrm{a}, \mathrm{b}, \mathrm{A}, \mathrm{B}-$ means $\pm \mathrm{SD}$ in rows marked with different small letters differ significantly at $\mathrm{P} \leq 0.05$, with capital letters - significantly at $\mathrm{P} \leq 0.01$. 


\section{Discussion}

The condition of sows depends mainly on appropriate feeding during the reproductive cycle. In the present study the sows were kept over three successive lactations under constant environmental conditions of a farm and were fed proper complete diets adjusted to their physiological status. On the day of selection, PLW and PL gilts maintained under such uniform environmental and feeding conditions had comparable body weight and P2 backfat thickness (Table 2). From this, it might be concluded that these breeds are similar but the differences between the analysed maternal breeds become more noticeable during subsequent breeding. Over the three reproductive cycles the PLW sows achieved significantly higher body weight and lower P2 backfat thickness in comparison with the PL sows. Differences in backfat thickness between the analysed maternal breeds were also reported by Knecht et al. (2014), who showed that on the day of first mating, the PLW sows had significantly lower backfat thickness compared to the PL sows.

\section{Effect of breed (PLW, PL) and polymorphism at the DGAT1 locus on BW and $P 2$ backfat thickness of the sows and on their reproductive performance in three reproductive cycles}

Under the same management and feeding conditions, breeds may differ in backfat thickness due to genotype. One of the genes affecting the body's lipid metabolism is the diacylglycerol acyltransferase 1 (DGAT1) gene. It codes for the microsomal enzyme DGAT1, which catalyses triglyceride synthesis in the small intestine (Lopaschuk et al., 2010), and also in the milk of sows (Lv et al., 2015). Analysis of the frequency of DGAT1 G/A 3'UTR (rs342152658) genotypes (Table 1) revealed three genotypes of this gene $(A A, A G, G G)$ in the PL breed and only one genotype $(G G)$ in the PLW breed. Thus, the effect of this gene was determinable only in the PL breed. In PL sows, G/A 3'UTR polymorphism of the DGAT1 gene showed a significant $(\mathrm{P} \leq 0.01)$ negative correlation with $\mathrm{P} 2_{\mathrm{G}}$ backfat thickness on selection day $(A A \rightarrow A G \rightarrow G G, \mathrm{r}=-0.208)$, and also in subsequent periods of the sows' reproductive cycle $\left(\mathrm{P} 2_{\mathrm{M}} \mathrm{r}=-0.192, \mathrm{P} 2_{\mathrm{F}} \mathrm{r}=-0.232, \mathrm{P} 2_{\mathrm{W}} \mathrm{r}=-0.214\right)$. It was also found that on farrowing day, the PL sows of the $D G A T 1^{A G}$ genotype had thicker P2 backfat by $2.33 \mathrm{~mm}$ compared to sows of the $D G A T 1^{G G}$ genotype $\left(\mathrm{P} 2_{\mathrm{M}}, A G>G G, \mathrm{P} \leq 0.05\right)$, which over the three reproductive cycles translated into better rearing performance of the piglets born to heterozygous females $(A G>G G, \mathrm{P} \leq 0.01)$, because proper condition of late-gestation sows (carcass protein and fat content) allows the mothers to have high lactational milk yield and, as a result, high weaning weight of the piglets (Decaluwe et al., 2013). What is more, comparison of the PLW and PL sows of the DGAT1 ${ }^{G G} 3^{\prime}$ UTR genotype revealed that during three reproductive cycles the PLW females had, especially on farrowing day, lower P2 backfat thickness (by an average of $1.24 \mathrm{~mm}$, $\mathrm{P} \leq 0.05$ ) and higher $\mathrm{BW}$ (by an average of $10.63 \mathrm{~kg}, \mathrm{P} \leq 0.01$ ) compared to the $\mathrm{PL}$ sows. However, the differences observed in the condition of these sows had no effect on the number and weight of piglets born and reared. Therefore, it can be stated that sows of maternal breeds with the $D G A T 1^{G G} 3^{\prime} U T R$ genotype are characterised by similar reproduction results. 
In the case of the $\mathrm{A} / \mathrm{G}$ rs45434075 DGAT1 mutation, our study showed (Table 3 ) that the PLW gilts with allele $A$ of this gene $\left(D G A T 1^{A A}\right.$ and $\left.D G A T 1^{A G}\right)$ in the genotype had lower P2 backfat thickness on selection day compared to the $D G A T 1^{G G}$ homozygous gilts $\left(\mathrm{P} 2_{\mathrm{G}}, \mathrm{AA}, \mathrm{AG}<\mathrm{GG}, \mathrm{P} \leq 0.05\right)$. A similar relationship was observed in the PLW sows on farrowing day $(\mathrm{AA} \rightarrow \mathrm{AG} \rightarrow \mathrm{GG}, \mathrm{r}=-0.214, \mathrm{P} \leq 0.01)$. However, no such relationships were found for the PL sows. It has to be noted that in the case of P2 backfat thickness on selection day, an interaction was also found between the breed and DGAT1 A/G polymorphism. The PLW sows of the $D G A T 1^{G G}$ genotype showed thicker $\mathrm{P} 2_{\mathrm{G}}$ also when compared to the PL sows of the $D G A T 1^{G G}$ genotype. It was also found that the PLW sows of the $D G A T 1^{A A}$ genotype, compared to PL sows of the same genotype, had 2-3 mm lower P2 backfat thickness in successive periods of the reproductive cycle $(\mathrm{P} \leq 0.01)$. However, the differences between the breeds and $D G A T 1 A / G$ genotypes did not have a significant effect on the production results of these females. The findings of other authors concerning the analysed polymorphism were similar as for the PL breed in our study. Weisz et al. (2011) in the Czech Large White and Renaville et al. (2015) in heavy pigs demonstrated that DGAT1 A/G polymorphism has no significant effect on backfat thickness in young animals. Also, for the A3122G DGAT1 (AvaII) polymorphism, Zuo Zuo (2008) showed that out of several pig breeds under analysis, this mutation significantly affected backfat thickness only in one breed (Yorkshire). Animals of the $A A$ genotype had lower backfat thickness compared to animals of the $G G$ genotype. In the Duroc and Landrace breeds, the same authors found no significant differences in backfat thickness between animals of these genotypes.

\section{Effect of interaction between DGAT1 locus mutations on P2 backfat thick- ness in sows of maternal breeds and on their reproductive performance in three reproductive cycles}

The different results of the study concerning the effect of a single DGAT1 gene on fattening traits of pigs of different breeds may be due to the effect of different SNPs of the genes on these breeds and different interactions between them (Fan et al., 2009; Kim et al., 2006). When analysing the effect of interaction between the SNPs of four genes on porcine fatness traits, López-Buesa et al. (2014) concluded that the selection of pigs based on genetic markers should account for the interaction between genes rather than the effect of a single gene. Our study also demonstrated a statistically significant effect of the interaction between the analysed genotypes (DGAT1/DGAT1 3'UTR, Table 5), mainly on backfat thickness on the day when young animals were selected $\left(\mathrm{P} 2_{\mathrm{G}}\right.$, Figure 1$)$. Animals of the $D G A T 1^{G G / G G}$ genotype had significantly higher $\mathrm{P} 2$ backfat thickness compared to most of the analysed genotypes. However, during their reproductive life these sows, compared to the other sows, had similar BW and P2 backfat thickness, and additionally reared the largest number of piglets over three lactations (with a significant difference in relation to sows of the $D G A T 1^{A A / A G}$ genotype, Figure 2). It was also established that sows of the $D G A T 1^{A A / A G}$ genotype, which on the performance test day had the lowest P2 backfat thickness (Figure 1), increased the value of this parameter during the three reproductive cycles, especially on the farrowing day and weaning day (highest values of all 
genotypes). Ultimately, these sows gave birth to the smallest number of piglets (with a significant difference in relation to the sows of the $D G A T 1^{A G / A G}$ and $D G A T 1^{A G / G G}$ genotypes, Figure 2).

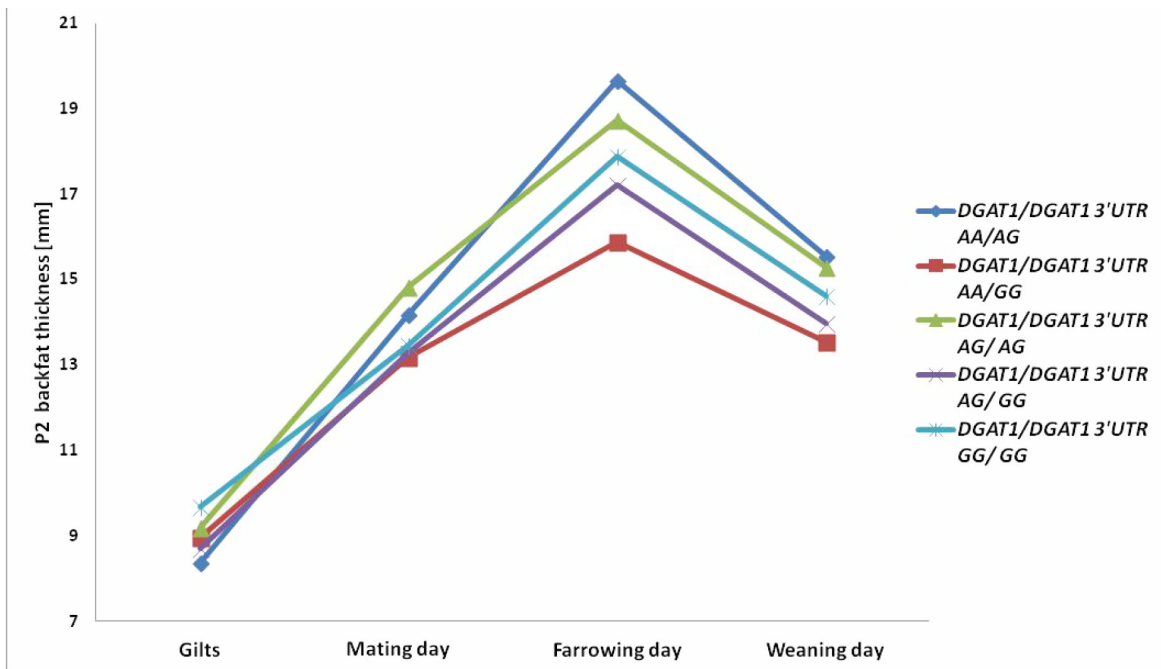

Figure 1. Mean P2 backfat thickness in sows during three reproductive cycles depending on genotype at the DGAT1 locus (DGATI/DGAT1 3'UTR)

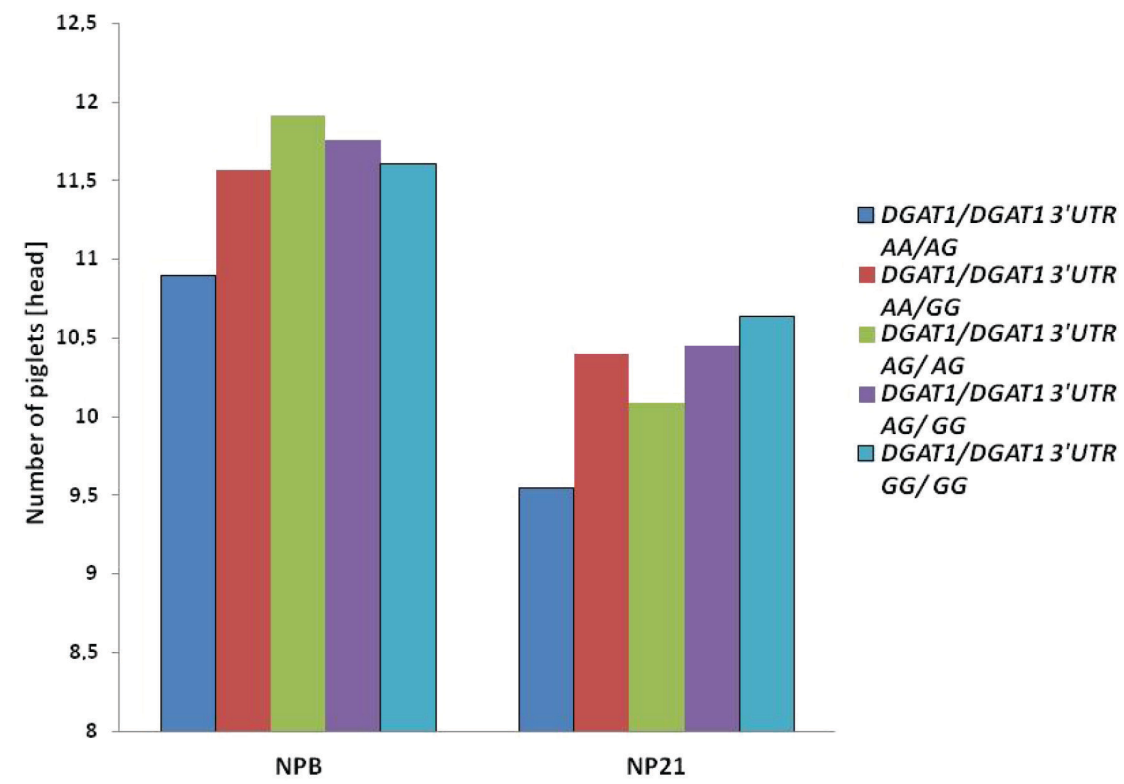

Figure 2. Mean number of piglets born and reared during three reproductive cycles depending on dam genotype at the DGAT1 locus (DGAT1/DGAT1 3'UTR) 
These results are consistent with the well-known observation that excessive fatness of sows in late gestation leads to reproductive disorders, including difficult births and lower number of piglets born alive (Beyga and Rekiel, 2009), whereas optimum fat reserves in the body of females guarantee good reproductive performance (Young et al., 2004). This being the case, the use of the analysed SNPs of the DGAT1 gene only to select gilts for lower P2 backfat thickness may adversely affect the production results of a pig farm. This is because elimination of animals of the $D G A T 1^{G G / G G}$ genotype (with the highest P2 backfat thickness on selection day) from breeding will, at the same time, exclude good mothers that will give birth to a comparable number of piglets as other sows, but at the same time they will rear 1.09 piglets more than sows with the lowest P2 backfat thickness on selection day (i.e. with the $D G A T 1^{A A / A G}$ genotype, $\left.\mathrm{P} \leq 0.05\right)$. On the other hand, gilts of the $D G A T 1^{A A / A G}$ genotype, when retained in the herd, will give birth, over three reproductive cycles, to 0.86 to 1.01 fewer piglets compared to sows of the $D G A T 1^{A G / G G}$ and $D G A T 1^{A G / A G}$ genotypes, respectively. It should also be remembered that the number of piglets born per litter can be significantly affected by mutations, especially in the genes involved in reproductive processes of the sows (Terman and Kumalska, 2012).

The results of our work indicate that among the sows of the $A A / G G, A G / A G$ and $A G / G G$ genotypes, which were characterised by similar fatness on the day of gilt selection as well as a similar number of piglets born, the $A G / A G$ heterozygous dams reared the heaviest piglets on $\mathrm{d} 21$ of age. This may be indicative that these sows are predisposed to produce, over three lactations, milk in the quantity and quality that ensures good rearing performance of the piglets (Decaluwe et al., 2013). Variation in the chemical composition of colostrum and milk depends on the breed (Migdał et al., 2005; Szyndler-Nędza et al., 2013), but also on the condition of the sows. In a study investigating the effect of P2 backfat thickness in sows, Rekiel et al. (2015) showed that sows with higher fatness produce milk with a significantly higher lactose content compared to thinner sows.

\section{Conclusions}

In summary, it may be stated that in the analysed populations of pigs of maternal breeds, a single mutation $(A / G)$ in the $D G A T 1$ gene (rs45434075) has a significant effect only in PLW gilts on deposition of subcutaneous fat $\left(\mathrm{P} 2_{\mathrm{G}}, A A, A G>G G, \mathrm{P} \leq 0.05\right.$ and $\mathrm{P} 2, \mathrm{~F}=214, \mathrm{P} \leq 0.01)$. In the case of $G / A$ 3'UTR polymorphism in the DGAT1 gene (rs342152658), only in the PL sows was this mutation $(A A \rightarrow A G \rightarrow G G)$ negatively correlated to the fatness of the sows during their reproductive life and to the weight of piglets reared to $21 \mathrm{~d}$ of age. The sows of the $D G A T 1^{G G}$ 3'UTR genotype had a significantly lower $\mathrm{P} 2_{\mathrm{F}}$ backfat thickness $(\mathrm{P} \leq 0.05)$, and during 21 -d lactation they reared significantly lighter piglets $(\mathrm{P} \leq 0.01)$ compared to sows of the same breed with the DGAT1 $1^{A G}$ 3'UTR genotype. The interaction between the DGAT1 mutations in sows of maternal breeds (DGAT1/DGAT1 3'UTR) had an effect on the analysed traits. The $D G A T 1^{G G / G G}$ sows had the highest P2 backfat thickness on selection day, and over three reproductive cycles reared significantly more piglets $(\mathrm{P} \leq 0.05)$ compared to the sows of the DGAT1 ${ }^{A A / A G}$ genotype. In addition, the DGAT1 ${ }^{A A / A G}$ sows, which showed the lowest P2 backfat thickness on selection day, gave birth to the 
smallest number of piglets during three reproductive cycles. Over three reproductive cycles, the $A G / A G$ heterozygous sows reared the heaviest piglets compared to the females of the $A A / G G$ and $A G / G G$ genotypes $(\mathrm{P} \leq 0.05)$.

\section{References}

B e y g a K., R e k i e 1 A. (2009). Effect of body condition and oxitocin administration on the course of parturition in sows and results of piglet rearing (in Polish). Rocz. Nauk. Zoot., 36: 45-53.

Buhman K.K., Smith S.J., S ton e S.J., Rep a J.J., Wong J.S., Knapp F.F.J., Burri B.J., H a m il t o n R.L., A b u m r a d N.A., F a r e s e R.V.J. (2002). DGATl is not essential for intestinal triacylglycerol absorption or chylomicron synthesis. J. Biol. Chem., 277: 25474-25479.

Decaluwé R., Maes D., Declerck I., Cools A., Wuyts B., De Smet S., Janss e n s G.P.J. (2013). Changes in back fat thickness during late gestation predict colostrum yield in sows. Animal, 7: 1999-2007.

F a n B., O n ter u S.K., P l a s t ow G.S., R o th s ch i ld M.F. (2009). Detailed characterization of the porcine MC4R gene in relation to fatness and growth. Anim. Genet., 40: 401-409.

H a u s m a n G.J., D od s on M.V., A juw on K., H a u s m a n G.J., D od s on M.V., A juw o n K., A za in M., B arne s K.M., Gu a n L.L., J i ang Z., P o ulos S.P., S a in z R.D., S mith S., S purlock M., Novakof ski J., Ferny hough M.E., B ergen W.G. (2009). Board sponsored invited review: the biology and regulation of preadipocytes and adipocytes in meat animals. J. Anim. Sci., 87: 1218-1246.

K i m K.S., L e e J.J., S h in H.Y., C ho i B.H., L e e C.K., K i m J.J., Cho B. W., K i m T.H. (2006). Association of melanocortin 4 receptor (MC4R) and high mobility group AT-hook 1 (HMGA1) polymorphisms with pig growth and fat deposition traits. Anim. Genet., 37: 419-421.

Knecht D., Środoń S., D uziński K. (2014). In vivo evaluation of the fat content and muscularity of gilts with different genotypes using an Aloka SSD-500 ultrasound scanner in relation to selected reproductive performance indicators (in Polish). Rocz. Nauk. PTZ., 10: 25-35.

L o p a s chuk G.D., U s she r J.R., F o $1 \mathrm{~m}$ e s C.D., J a s w a 1 J.S., S t a n 1 e y W.C. (2010). Myocardial fatty acid metabolism in health and disease. Physiol. Rev., 90: 207-258.

Ló pe z-B u e s a P., B urg os C., G a lve A., Var on a L. (2014). Joint analysis of additive, dominant and first-order epistatic effects of four genes (IGF2, MC4R, PRKAG3 and LEPR) with known effects on fat content and fat distribution in pigs. Anim. Genet., 45: 133-137.

L v Y., Gu an W., Q i a o H., Wan g C., Ch en F., Z hang Y., L i a o Z. (2015). Veterinary medicine and omics (veterinomics): Metabolic transition of milk triacylglycerol synthesis in sows from late pregnancy to lactation. OMICS, 19: 602-616.

Matysiak B., Kawę cka M., Kołodziej A., Sosnowska A. (2007). Relationships between body weight of primiparous sows in pregnancy and their reproductive performance. Acta Sci. Pol. Zootechnica, 6: 25-32.

Migdał W., Koczanowski J., Klocek C., Tuz R., Paściak P., Wojtysiak D., Orlick i S. (2005). Chemical composition of colostrum and milk from Polish Landrace and Polish Large White sows. Ann. Anim. Sci., Suppl., 1: 43-46.

N o n n e m a n D., R o hrer G.A. (2002). Linkage mapping of porcine DGAT1 to a region of chromosome 4 that contains QTL for growth and fatness. Anim. Genet., 33: 472-473.

Rekiel A., Więcek J., Beyga K. (2011). Analysis of the relationship between fatness of late pregnant and lactating sows and selected lipid parameters of blood, colostrum and milk. Ann. Anim. Sci., 11: 487-495.

Rekiel A., Wi ęc e k J., K u c zy ńsk a B., B artos i k J., Ward a A., F urman K. (2015). Effect of the backfat thickness at point $\mathrm{P}_{2}$ during insemination on the selected parameters of colostrum and milk of the sows. Ann. Warsaw Univ. Live Sci. - SGGW Anim. Sci., 54: 153-160.

Renaville B., B acciu N., Lanzoni M., Corazzin M., Piasentier E. (2015). Polymorphism of fat metabolism genes as candidate markers for meat quality and production traits in heavy pigs. Meat Sci., 17: 220-223. 
Szczerbal I., Li L., Stachowiak M., Chmurzyńska A., Maćkowski M., Winter A., F lisikowski K., Fries R., Świtoński M. (2007). Cytogenetic mapping of DGAT1, PPARA, ADIPOR1 and CREB genes in the pig. J. Appl. Genet., 48: 73-76.

$\mathrm{S}$ z y n d l e r - N ę d z a M., P i ó r k ow s k a K. (2015). Effect of DGATl gene mutation in sows of damline on the composition of the produced milk and piglet rearing during 21-day lactation. African J. Biotech., 14: 2478-2483.

Szyndler-Nędza M., Tyra M., Ropka-Molik K., Piórkowska K., Mucha A., Róż y c k i M., K o s k a M., S z u lc K. (2013). Association between $L E P R$ and $M C 4 R$ genes polymorphism and composition of milk from sows of dam line. Mol. Biol. Rep., 40: 4339-4347.

Term a n A., K u malsk a M. (2012). The effect of a SNP in ESR gene on the reproductive performance traits in Polish sows. Russian J. Genet., 48: 1260-1263.

We is z F., Urban T., Ch a 1 u p ow a P., Knoll A. (2011). Association analysis of seven candidate genes with performance traits in Czech Large White pigs. Czech J. Anim. Sci., 56: 337-344.

Wi entje s J.G.M., S o ede N.M., Knol E.F., Van den Brand H., Ke mp B. (2013). Piglet birth weight and litter uniformity: Effects of weaning-to-pregnancy interval and body condition changes in sows of different parities and crossbred lines. J. Anim Sci., 91: 2099-2107.

Young M.G., Tokach M.D., Aherne F.X., Main R.G., Dritz S.S., Goodband R.D., $\mathrm{Ne}$ ls s e n J.L. (2004). Comparison of three methods of feeding sows in gestation and the subsequent effects on lactation performance. J. Anim. Sci., 82: 3058-3070.

Zh a n g C.Y., Wa ng Z., B ru c e H.L., J an z J., G od d ard E., M o ore S., P 1 a s to w G.S. (2014). Associations between single nucleotide polymorphisms in 33 candidate genes and meat quality traits in commercial pigs. Anim. Genet., 45: 508-516.

$\mathrm{Z}$ u o $\mathrm{Z}$ u o Y. (2008). Studies on SNPs of DGAT1 gene and its association with partial economic traits in pigs. Dissertation, Hunan Agricultural University. http://www.dissertationtopic.net/doc/497147.

Received: 11 IV 2017

Accepted: 31 V 2017 